\title{
The Strange Resilience of New Public Management: the case of medical research in the UK's National Health Service
}

\section{Authors:}

Dr. Louise Caffrey, School of Social Work \& Social Policy, Trinity College Dublin.

Professor Ewan Ferlie, King's Business School, King's College London.

Professor Christopher McKevitt, Department of Primary Care \& Public Health Science, King's College London.

\section{Original Citation:}

Caffrey, L., Ferlie, E., McKevitt, C. (2018) The Strange Resilience of New Public Management: the case of medical research in the UK's National Health Service. Public Management Review Doi: https://doi.org/10.1080/14719037.2018.1503702

Available at: https://www.tandfonline.com/doi/full/10.1080/14719037.2018.1503702

Article (Accepted Version)

Refereed 


\begin{abstract}
Whether New Public Management (NPM) ideas and practices have remained resilient or are now in decline remains a topic of contention. We investigate the case of a national system, introduced in 2006, for performance managing medical research in the United Kingdom's National Health System (NHS). We argue that the system conforms to traditional NPM, providing empirical evidence of its late adoption and resilience. We highlight potential conflicts in the adoption of NPM in this context and demonstrate for the first time the potential for this NPM-style system to produce unintended and unwanted consequences in the context of medical research.
\end{abstract}

\title{
Key Words
}

New Public Management; performance management; medical research; NHS. 


\section{Introduction}

Debate continues in the field of public management scholarship as to whether there has been a paradigm change indicating the end of dominance by the model of New Public

Management (NPM). While major NPM reforms were strongly evident in UK public services (for example in the introduction of general management, corporate Boards and a quasimarket in the NHS) in the 1980s and 1990s, they have also been criticised for dysfunctional effects, including: excessive inter-agency fragmentation and silo based working (Dunleavy et al, 2006), the disengagement of professionals and a growing democratic deficit (Newman, 2001) together with excessive performance management and top down control (Bevan and Hood, 2006) which then result in organizational gaming and short termism. Whether or not such NPM 'reforms' have endured in practice is both an open and a major question.

Recent attempts to move beyond NPM approaches to public management reforming in the UK are evident, perhaps informed by these criticisms. At a meta level, the academic development (Newman, 2001; Osborne, 2009; Rhodes, 1997; Rhodes, 2007) and (the partial) appropriation in the policy domain of the so called "Network Governance" (NG) reform narrative as an antidote to earlier NPM reforms was evident in the New Labour period (19972010). Guiding NG ideas stress a range of softer values and associated policy mechanisms, including: collaboration, networks and partnership; the greater involvement of civil society and the third sector; staff reengagement after a period of managerialist excesses and democratic revitalisation. In practice, NG reforms were often mixed with enduring NPM elements, such as performance management.

More specifically, the English health care sector was characterised by some important NG reforms in the 2000s. There was greater use of partnerships, whole systems working and 
managed networks to deliver major service improvement objectives. For example, the 2000 NHS Cancer Plan led to the creation of sub-regional managed cancer networks (Ferlie, 2013) as a 'delivery vehicle'. A new patient safety and quality agenda emerged which led to an increased interest in techniques which could help promote goals of service improvement, such as quality management models. There was a broadening of perspective beyond the old NPM themes of sharper operational management, efficiency savings and ramping up productivity.

There was also an attempt to develop and engage clinical leadership going beyond reliance on the narrow general managerial cadre favoured by earlier NPM reforms (Griffiths, 1983). There was now increased stress on working with civil society and the promotion of more effective user involvement, notably so in the mental health sector. Many of these wider themes were strongly expressed in the health policy domain in the Darzi Report (Department of Health, 2008), published towards the end of the New Labour period. Themes of organizational learning, staff and user engagement were stressed again in the Berwick Report (2013) as it tried to unpick lessons from major failures at the Mid Staffordshire NHS Trust.

Given these developments, some argue the problems of NPM are now being addressed through post-NPM reform, that NPM is 'dead in the water' (Dunleavy, Margetts, Bastow, \& Tinkler, 2006, p. 468) and that other models are rising (Bryson, Crosby, \& Bloomberg, 2014; Dunleavy et al., 2006; Osborne, 2009). Others, however, have suggested that NPM remains embedded and resilient in the United Kingdom (UK) and other high NPM jurisdictions, despite operating dysfunctionally (De Vries \& Nemec, 2013; Ferlie \& Fitzgerald, 2002; Ferlie et al, 2011; Ferlie \& Ongaro, 2015; Lodge \& Gill, 2011; Trenholm \& Ferlie, 2013). This debate about resilience or decline of the NPM model is therefore of particular importance since the NPM model has been the subject of criticism given evidence of dysfunctional effects. 
In this paper we explore a national system for performance managing medical research in the UK's NHS which was introduced as part of the National Institute for Health Research (NIHR), founded in 2006. We explore the following research question: Do staff experiences and perceptions indicate the potential for unintended or unwanted consequences due to the NIHR Local Clinical Research Network (LCRN) performance management system? We discuss whether this system for allocating infrastructural funds to medical research in the NHS constitutes an example of NPM resilience or decline.

Empirically, this paper contributes data on the work practices and systems of the NIHR, an important but relatively recently created agency, and one that has received scant scholarly attention. Theoretically, it contributes to the debate on whether NPM is in decline or remains resilient. We provide evidence of continued resilience of the NPM model in the English health sector (specifically, in the area of health research), a surprising finding perhaps given the model's liability for dysfunctional features. We argue that the NIHR's performance management system conforms to traditional NPM principles, providing recent evidence of the late-adoption of NPM in an additional sector and the resilience of this paradigm in the UK. Through a case study of a high-performing NHS Trust we demonstrate the potential for this NPM-based performance management system to produce unintended and unwanted consequences. The paper highlights the need for further public management research on NIHR organisational practices and contributes new knowledge to the debate surrounding the resilience or decline of NPM.

\section{The New Public Management}

Since the 1980's the public sector in the UK, as in some other OECD countries, has been subject to a linked set of politically and ideologically motivated reforms often referred to as 
the 'New Public Management' (Hood, 1991) and the UK's National Health Service (NHS) has been held up as an index case for NPM reforms (Ferlie, Ashburner, Fitzgerald, \& Pettigrew, 1996). NPM doctrine claims to seek economy, efficiency, effectiveness in its redesign of public services, and to restore governability by taking power back from allegedly over-mighty public sector trade unions and professionals. It is characterised by top-down control, greater emphasis on output controls, disaggregation of the public sector into corporatized units, a shift to greater competition, greater flexibility in hiring staff and stress on cutting direct costs (Hood, 1991).

More recently it has been suggested that under NPM, performance management has become the core of public management control strategies (Van Dooren, Bouckaert, \& Halligan, 2015). Indeed, such is the current focus on performance that NPM has been referred to as a 'performance movement' (Van Dooren et al., 2015, p. 48) and authors refer to the rise of 'government by performance management' (Moynihan \& Pandey, 2005) 'the new evaluation state' (Henkel, 1991), the 'regulatory state' (Day \& Klein, 1990) and an 'audit society' (Power, 1997).

There exists a large body of literature investigating the effects of New Public Management. Many authors contest the success of NPM (Hood, 2006; Kelman \& Friedman, 2009; Loveday, 2008; McCann et al, 2015; Pollitt \& Dan, 2011; Simonet, 2014; Smith, 1993; Verbeeten \& Speklé, 2015) and the literature further documents numerous unintended consequences (Bevan \& Hood, 2006; Hood \& Peters, 2004; Lester et al, 2011; Mannion \& Braithwaite, 2012; Smith, 1995; Wankhade, 2011).

In part, disagreement centres on differing definitions of success. While the value system underlying NPM reform emphasises criteria such as value for money, productivity and the efficacy of competition (Hood, 1991), the literature evidencing its unintended consequences 
tends to define success more broadly. Measurement systems are rarely unobtrusive and risk influencing behaviour and there is concern that NPM models may encourage organisations to "[hit] the target and miss the point" (Bevan \& Hood, 2006, p. 521). Smith (1995), for example, has grouped unintended consequences into categories, including, for example, 'suboptimisation' and 'measure fixation'. In the former, workers focus narrowly on measured local objectives at the expense of the objectives of the organisation as a whole. In the latter, workers pursue strategies which enhance the reported measure rather than wider associated objectives. As measures provide a snapshot, they may encourage myopia. The literature refers to 'gaming', the deliberate manipulation of behaviour to secure strategic advantage (Smith, 1995).

Highlighted empirical examples of such behaviour in the English NHS include, general practitioner practices responding to a target to see their patients within 48 hours by refusing to book any appointments more than 48 hours in advance (Bevan \& Hood, 2006); patients being left to wait in ambulances outside the hospital until staff were confident of meeting a target for less than 4 hour wait in A\&E (Commission for Health Improvement, 2004); treatments commencing but not being completed in situations in which the performance management indicator only measured commencement (Hood, 2006). In a landmark case in England, the inquiry into sub-standard care in the Mid Staffordshire Foundation Trust found that "patients were routinely neglected by a trust that was preoccupied with cost cutting, targets and processes and which lost sight of its fundamental responsibility to provide safe care" (Francis, 2013).

Critiques of NPM-style performance management highlight key obstacles to its success. For example, Lewis (2016) asserts that NPM-style management of health care has, paradoxically, led to simultaneously too much and too little performance measurement and management. The accusation of too much refers to the expansion of these practices across the sector, 
creating a potentially bewildering array of performance frameworks. Meanwhile, a management deficit would seem evident from the high profile cases cited above, where services achieving high performance on indicators have subsequently been shown to be providing sub-standard care. Moreover, the tendency to select only those indicators for which data are available can bias measurement towards measurable dimensions, leading to concept reduction and deficits in understanding broader practice. Ultimately, performance data are often unavailable for the concept managers wish to measure (Van Dooren et al., 2015). Further, while the English health system has embraced the concept of learning for the purpose of enhanced patient safety and service improvement (Department of Health, 2000), NPM-style systems have been criticised for the barriers they present to learning (Senge et al, 1994) due to concept reduction and the potential conflict between accountability (which may dis-incentivise highlighting weaknesses) and learning (which requires identifying weaknesses) (Tan \& Harvey, 2016; Van Dooren et al., 2015).

Specifically in relation to the management of health research, Croxson and colleagues (2001) highlight that the standard approach to managing performance involves using uniform performance indicators that can be specified in advance and evaluated at well-defined intervals. However, this approach is extremely difficult to apply to $R \& D$ since research is rarely a linear process with end points predictable in advance. Indeed, it is not always possible or desirable to pre-specify appropriate research outcome based targets. Croxson and colleagues (2001) theorise that targets specified in advance may bias research effort towards less risky projects. Indeed, systematic control through performance management may inhibit the exploratory, creative behaviour required for successful research (Ouchi, 1977, p. 99). Further, research suffers an attribution problem: it is not always possible to attribute an outcome to a specific piece of R\&D. Rather, outcomes are often the result of cumulative efforts and considerable time may pass before a project bears fruit, making it difficult to link 
outcomes to annual investment. Given the variety of project types, standard performance indicators may not be suitable for all programmes and activities (Croxson, 2001).

Discussing potential models of health research management in the NHS, Croxson and colleagues (2001, p. 228) argued that, given the limitations set out above, R\&D performance management systems should not attempt to set uniform targets in advance. Instead the system should aim to meet an alternative set of five criteria: it should be relevant to funder's objectives, be decision-relevant, encourage truthful compliance, minimise unintended consequences and have acceptable net costs. Measurement, should be multi-dimensional, incorporating both qualitative and quantitative feedback. While these proposed criteria are not sufficiently specific to set out a management regime they highlight a desire for a broader style than the quantitative, financial-accountability approach characteristic of NPM. Other authors have also called for systems to collect a mix of quantitative and qualitative data, and "soft intelligence" to tailor inspection towards local circumstances and assess aspects of performance that defy ready quantification (Bevan \& Hood, 2006; Mannion \& Braithwaite, 2012). Indeed, research with senior healthcare leaders in the NHS has found widespread agreement concerning the limitations of formal metrics for monitoring quality and safety and the importance of incorporating 'soft intelligence' (Martin et al, 2015). Further, the key public inquiry in England into sub-standard hospital care, which was critical of over-reliance on quantitative indicators, recommended that to prevent future similar tragedies hospital needed to take greater heed of the insights of staff, patients and carers by paying greater attention to narratives (Francis, 2013).

In summary, therefore, there is evidence that NPM does not necessarily achieve intended effects and may dysfunctionally distort what it claims to measure, creating unintended consequences. (Shore, 2008; Smith, 1995). Its success is therefore contested based on 
differing underlying value models. Alternative models have proposed a greater focus on qualitative data and staff and patient narratives to inform broader understanding of practice.

\section{NPM: resilience or decline?}

There has been considerable debate about whether there is evidence of a post-NPM configuration. Various authors have argued that we are indeed observing a paradigm change and that this shift in managerial ideas and practices is overcoming NPM related weaknesses. Osborne (2006), for example, suggests that NPM may be a transitory stage in the evolution to New Public Governance (NPG) and Bryson and colleagues (2014) claim we are seeing the demise of NPM and rise of Public Value Governance. Christensen and Laegreid (2008) suggest there has been a reassertion of old public administration practices due to the failures of NPM. Dunleavy and colleagues (2006) have argued that in key 'leading edge' countries (the UK, USA, Australia, New Zealand, Canada, The Netherlands and Japan), NPM has been 'largely stalled or reversed' and that Digital Era Governance (DEG) is emerging as a new paradigm (Dunleavy et al., 2006, p. 467).

Others are more sceptical in their assessment of NPM demise (Dawson \& Dargie, 1999; Ferlie \& Fitzgerald, 2002 ; Ferlie et al., 2011; Ferlie \& Ongaro, 2015; Trenholm \& Ferlie, 2013). Focusing on the case of the organizational response to resurgent tuberculosis in the English NHS, they acknowledge some changes in emphasis in NPM doctrine, for example, more recent emphasis on management and less on markets (Ferlie \& Fitzgerald, 2002). However, their case study suggests NPM remains resilient and embedded, despite its dysfunctionality in addressing complex, system level problems such as the one studied (Trenholm \& Ferlie, 2013). Lodge and Gill (2011) found only limited evidence of a shift to post-NPM in New Zealand, another leading NPM jurisdiction. De Vries (2010) contends that 
changes have been modest and the NPM paradigm is 'in trouble, but is not really dead' (p.91). De Vries and Nemec (2013) assert that some countries are still implementing NPMtype reforms, including downsizing or introducing performance management but that other countries have chosen to implement alternative paradigms. Overall, therefore the academic debate continues as to whether NPM has been resilient or is in decline.

\section{Management of Medical Research in the NHS}

Internationally there has been increasing focus on creating 'health research systems' that integrate medical research and clinical care (World Health Organization, 2004) and the UK (along with Canada) is recognised as a pioneer in this field (Hanney \& González Block, 2006). Since the 1990's Research \& Development (R\&D) has been a core activity in the NHS along with a focus on the management of funding for R\&D (Feehally, 2002). These developments were consolidated in 2006 when the English Department of Health (DoH) established the National Institute for Health Research (NIHR), one of whose tasks is to develop and support the infrastructures needed to embed a health research system in the NHS (Department of Health, 2006).

The drive to systemically develop the UK's capacity to undertake medical research has taken place in the context of a national push to strengthen the knowledge based economy. Health research has therefore been positioned as a driver of both health and wealth (Department of Health, 2006). Studies have suggested that economic value has become a key force shaping health research policy in the UK as well as elsewhere (Shaw \& Greenhalgh, 2008; Stoneman, 1999). In particular, the life sciences industry has been seen as of great economic significance to the UK economy by successive governments and key economic central departments (Cooksey, 2006; Department of Business, 2011 ), an economic policy 
strengthened by the financial crisis of 2008 which discredited the old UK model of a predominant banking and finance sector. Integral to policy underpinning the importance of health research is an emphasis on increasing the number of patients in trials (and their speedier recruitment) to accelerate the development of therapeutic products (Shaw and Greenhalgh, 2008). Indeed, Shaw and Greenhalgh's analysis of UK health research policy concluded that research is reduced to numbers recruited into trials, with endorsement of particular practices based on a 'high-turnover model' where large numbers of patients are recruited to research (Shaw \& Greenhalgh, 2008, p. 2516).

As noted above, the NHS is an index case of NPM. Indeed, Greer and Jarman, (2007, p. 7) have described the Department of Health as 'one of the purest products of the deliveryoriented, business like 'new public management' that has been orthodoxy in the UK since the 1980's'. In addition, Martin and colleagues (2017) have argued that the global recession of 2008 strengthened a trend in the NHS, evident from 2005, away from increasing capacity to increasing productivity and that this new financial environment saw government seek to increase the influence of the market and corporate logics on the health system, including increased managerialism, performance management and competition. They suggest that areas of the health system previously immune to the influence of the market, from 2006 became subject to it. However, with the notable exception of Shaw and Greenhalgh's (2008) work, discussed above, the NIHR, as a relatively recently instated component of the DoH, has not been subject to analysis of its organisational systems.

Many of the 'doctrinal components' of NPM identified by Hood (1991) are evident in the NIHR's foundational document, Best Research for Best Health (Department of Health, 2006). The need for professional management of the new health research system is articulated, and includes streamlined systems for knowledge management that will reduce bureaucracy and deliver efficiency (Goal 4 of the strategy). Performance management is proposed so that the 
strategy will 'operate under clear and robust management arrangements supported by programmes of evaluation' (p.34) entailing explicit contractual arrangements, financial monitoring and control, clear lines of accountability and reviews of outputs and outcomes as well as value for money. It is also proposed that the goal to accelerate the initiation of research and increase its volume will be monitored and these research performance data made public. Goal 5 of the strategy focuses on value for money, identifying the ways in which the strategy will act 'as sound custodians of public money' (p.31). This will include setting up methods to evaluate the outcomes of funding investment. Competition is integral to the strategy. While the aim is to encourage research activity across all patients and professionals in England, and to use a population-based approach towards funding, it is also made clear that funding allocation will be competitive with awards made 'to those organisations that are truly outstanding in international research terms' (p.33). It is acknowledged that this will lead to 'resources being allocated to a relatively small number of organisations whose location will be determined by excellence' (p.33). These principles are evident and amplified in the NIHR's own presentation of its structure and organisation (NIHR, 2017a, 2017d). The lines of management are made explicit with identified leaders, advisory boards and management systems organized 'around products' (Hood 1991). The principles of competitiveness, value for money and performance management are also articulated.

The NIHR's performance management structure is provided through its Clinical Research Network (CRN), made up of 15 Local Clinical Research Networks (LCRN) (NIHR, 2014a). The CRN provides funding additional to NIHR's grant funding for studies. Grant funding is allocated on the basis of peer review but CRN funding, which provides infrastructural support for research, is allocated through a different process. Hospital Trusts in which research is conducted are required to monitor and report to LCRN the numbers of patients recruited to studies receiving LCRN infrastructural funding. These data are published in annual national 
league tables, which rank Trusts by the number of patients recruited in the previous year and the number of studies undertaken (NIHR, 2017c).

In $2014 / 15$, when the data for this research was collected, $73 \%$ of the NIHR’s £296 million to LCRN's was allocated on the basis of 'research activity' i.e. the number of patients hospital trusts in that network recruited to research studies in the previous year (NIHR, 2014c). Across the NIHR, patients recruited to studies accrue a value weighted by the type of study they take part in (large trial, observational study or study that includes an intervention). Funds are then allocated back to hospital Trusts on the basis of weighted patient numbers plus the other (more minor) factors outlined below in Figure 1 (NIHR, 2017b). In this study site, the Trust then redistributes funds back to services according to their recruitment success. Since 2014/15 the NIHR LCRN model has further included a 'performance based' metric, with $1.2 \%$ of total funding allocated on the basis of the LCRN meeting the target of $80 \%$ of studies meeting the 70 day target to recruit a first patient to each study (NIHR, 2017e). The Trust we examined had not included this in its redistribution of funds back to directorates although there was an expectation that it may do so in future.

Figure 1 outlines the NIHR LCRN funding allocation for $2017 / 18$. In this year, $78.2 \%$ of the $£ 284.6$ million was allocated based on 'research activity' (compared to $73 \%$ in 2014/15). 'Research activity' remained principally focused on the number of patients recruited, but $8.3 \%$ of this $78.2 \%$ was allocated based on the number of studies the LCRN led on (NIHR, 2017b). In 2014/15 an additional £11.7 million was allocated as "Research Capacity Funding", half of which was allocated evenly between LCRN and half allocated on the basis of the number of patients recruited. With this exception, the allocation categories are consistent between 2014/15, when this study was carried out, and the current 2017/18 model. 
Figure 1: NIHR Local Clinical Research Network Infrastructural Funding Allocations 2017/18
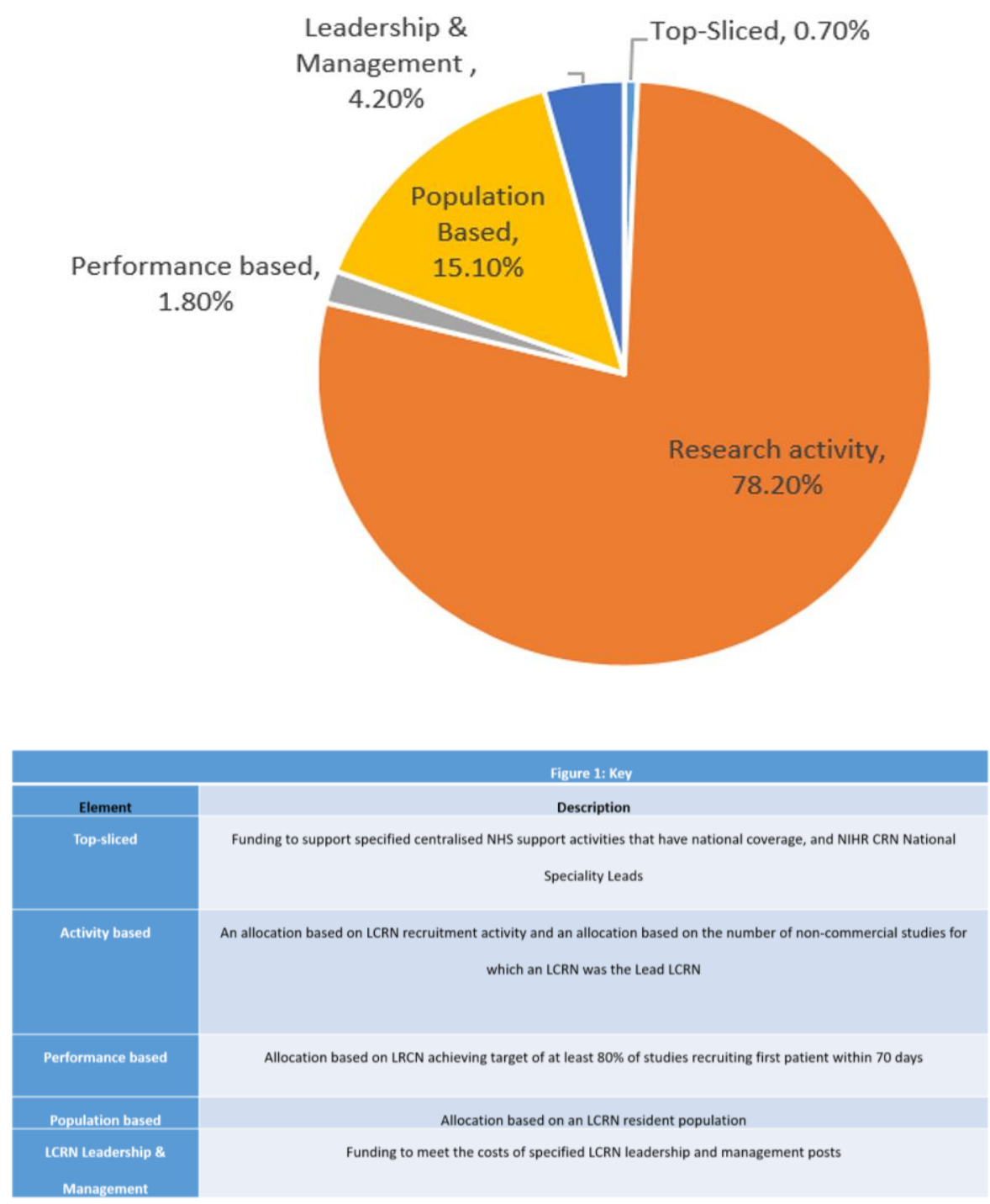

Therefore, the CRN provides a mechanism within NIHR to performance manage research at a national level using simple quantitative indicators, competitive league tables and financial incentives. To the best of our knowledge, no study has empirically investigated the implications of this regime for the debate surrounding the 'death' of NPM and the appropriateness of this regime for managing medical research. These questions are the focus of the current research study. 


\section{Methods}

Having set out the national functioning of the NIHR performance management system above, we undertook an in-depth investigation of its Trust-level functioning in a large inner-city Trust in England, comprising two teaching hospitals. The Trust is a high performer in the NIHR system, ranked in the national top ten Trusts for number of clinical studies and number of patients recruited to these studies (NIHR, 2014b). The purpose of the Trust-level study was to examine the potential consequences of the national NIHR performance system. As the first study in this area, it was exploratory in nature. The aim was not to study the prevalence of consequences and we make no claims in this regard.

Four clinical services within this Trust were recruited to take part in the case study. Services are anonymised to protect identities but were purposively sampled to ensure we included a range of specialities and research types. We further sought to include a wide range of staff in these services. This included, clinical staff (both doctors and nurses) without a specific research remit, referred to here as 'clinically-focused' staff; secondly, doctors actively carrying out research, referred to here as 'research-focused' doctors; thirdly, research nurses, coordinators and managers, whose remit is research. Finally, because of their influence in allocating resources, we sought to include service-level managers. Sampling reached theoretical saturation within our four case study services. It is nonetheless possible that an expansion of the number of case study services may have led to the development of further themes. This was not possible within the budgetary confines of this study.

Focus groups were adopted for both pragmatic and epistemological reasons. Pragmatically, focus groups are less resource intensive than individual interviews. Epistemologically, we were interested in the dynamics between members of the groups, assuming that meaning can 
be created through interactions in groups. We were further interested in potential disagreements between members of groups and sought to observe professionals challenge each other in this respect. While providing these advantages, it is important to note potential weaknesses of the focus group method: groups may stifle individual voices and can be difficult to recruit to (Bryman, 2008).

With the aim of creating a dynamic where individuals would feel more comfortable contributing to discussion, where possible focus groups were organised to comprise individuals doing the same job e.g. clinical nurses were separated from research nurses. Outside of this division, separating professionals proved difficult in practice as busy participants tended to turn up to whichever group they could attend. In Service A and C clinically focused doctors were in the same focus group as research-focused doctors and in all groups, those in management roles were placed in groups with research-focused staff for the pragmatic reason that doing so made it possible to include a wider variety of professionals. Participants were recruited through Research \& Development Leads in each service who were asked to email staff the participant information leaflet and consent form as well as an invitation to participate in the research. Participants were provided with a light lunch to incentivise participation.

The study's original research questions were: a) what barriers and enablers do staff face in recruiting patients to research? b) How do staff experience and perceive the CRN system? The study's original focus was pragmatic and centred on an organisational desire to understand and address barriers to patient recruitment. The current paper's focus was arrived at through theoretical induction. Our analysis moved from the initial broad, pragmatic focus of the study through to the specific theoretical issues established in the literature as it became apparent that our data was an interesting case study of the theoretical debate surrounding NPM resilience and decline. This paper therefore focuses on the following question: Do staff experiences and 
perceptions indicate any unintended or unwanted consequences due to the NIHR LCRN performance management system? In addition, in this paper we discuss whether the NIHR LCRN performance management system constitutes an example of NPM resilience or decline.

The data were collected between February and June 2015. The focus groups and interviews were audio-recorded and transcribed in full. The data were managed using Nvivo 10 software and analysed thematically. We drew on Spencer and colleagues' 'analytic hierarchy', moving iteratively from descriptive coding through to themes, concepts and the application of NPM theory (Spencer, Ritchie, \& O'Connor, 2003, pp. 213-215). By this means we moved inductively from coding of the broad themes to specific theoretical constructs. In keeping with the strategies proposed by Mays and Pope (2000), both positive and negative cases of theoretical constructs were coded and incorporated into the analysis. The first author coded the data and undertook the analysis while discussing data, findings and emerging theoretical constructs with the other authors. This provided opportunities for analytic challenge and development.

The Trust's R\&D Department approved the study and confirmed that ethical review was not required. Written informed consent was sought from all participants. Participants have been anonymised in this report. All participants were emailed the transcript of their interview/focus groups and offered the opportunity to amend anything they had said. Four participants made minor edits.

In total, 56 staff took part in ten focus groups and three one-to-one interviews. The interviews were undertaken when, unexpectedly, only one person turned up to two focus groups and when a key individual was unable to attend a focus group. Participant details are provided in Table 1. Focus groups averaged 51 minutes, while interviews averaged 27 minutes. 
TABLE 1: Participants by Service and Role

\begin{tabular}{|l|l|l|l|l|l|}
\hline & Service A & Service B & Service C & Service D & Total \\
\hline Research Nurses* (RN) & 3 & 3 & 6 & 6 & $\mathbf{1 8}$ \\
\hline Research-focused & 2 & 5 & 5 & 7 & $\mathbf{1 9}$ \\
\hline $\begin{array}{l}\text { Clinically-focused } \\
\text { Nurses*** (RD) }\end{array}$ & 3 & 0 & 1 & 6 & $\mathbf{1 0}$ \\
\hline $\begin{array}{l}\text { Clinically-focused } \\
\text { Doctors*** }(\mathrm{CD})\end{array}$ & 1 & 0 & 5 & 0 & $\mathbf{6}$ \\
\hline $\begin{array}{l}\text { Department } \\
\text { Managers***** (SM) }\end{array}$ & 3 & 0 & 0 & 0 & $\mathbf{3}$ \\
\hline Total & $\mathbf{1 2}$ & $\mathbf{8}$ & $\mathbf{1 7}$ & $\mathbf{1 9}$ & $\mathbf{5 6}$ \\
\hline
\end{tabular}

* Includes research coordinators, one research assistant and one research manager

**Includes doctors with academic posts and those with some allocated research time. Includes research fellows.

*** Includes one Allied Health Professional

**** Doctors with no allocated research time

*****Service manager, general manager and admissions manager

Some of our Trust case study services had more participants or a better spread of roles than others. It was particularly difficult to recruit clinical staff to the study and we were unable to recruit any clinical nurses in Department B and only recruited one nurse in Department C. Similarly, it was difficult to recruit service-level managers. This may have been because it was more difficult to convince clinically-focused and management staff that this research was relevant to them. 


\section{Results}

Our key findings relate to audit-style management and measurement; the flexibilisation of research nurse staff; and staff reports of potential unintended consequences of these practices, including measure fixation, staff recruitment and retention difficulties and gaming.

\section{Audit-style management \& measurement}

Our findings echo the literature suggesting a liability in NPM-style management for concept reduction and deficits in understanding broader practice (Van Dooren et al., 2015). In this domain of health research, we found strong performance management and measurement but of a limited range of activities. As Lewis (2016) observes, the performance focus in NPM can create a paradoxical excess of performance frameworks coupled with a management deficit, evidenced in high profile cases where health services achieving high performance on indicators have subsequently been shown to be providing sub-standard care.

Participants in all services reported that LCRN funding was vital to their ability to do research because, although grant funding makes up the bulk of funding for studies. Such funds to support infrastructure were known to be allocated based on previous success in numbers of patients recruited as well as type of study they were recruited to. Thus recruitment success translated into the allocation of funding from the NIHR to LCRN (as described above), but also, in turn, from this LCRN to the Trust and then from the Trust to the individual hospital services. This funding flow is visualised below in Figure 2. 


\section{Figure 2: Funding flow in case study LCRN \& Trust}

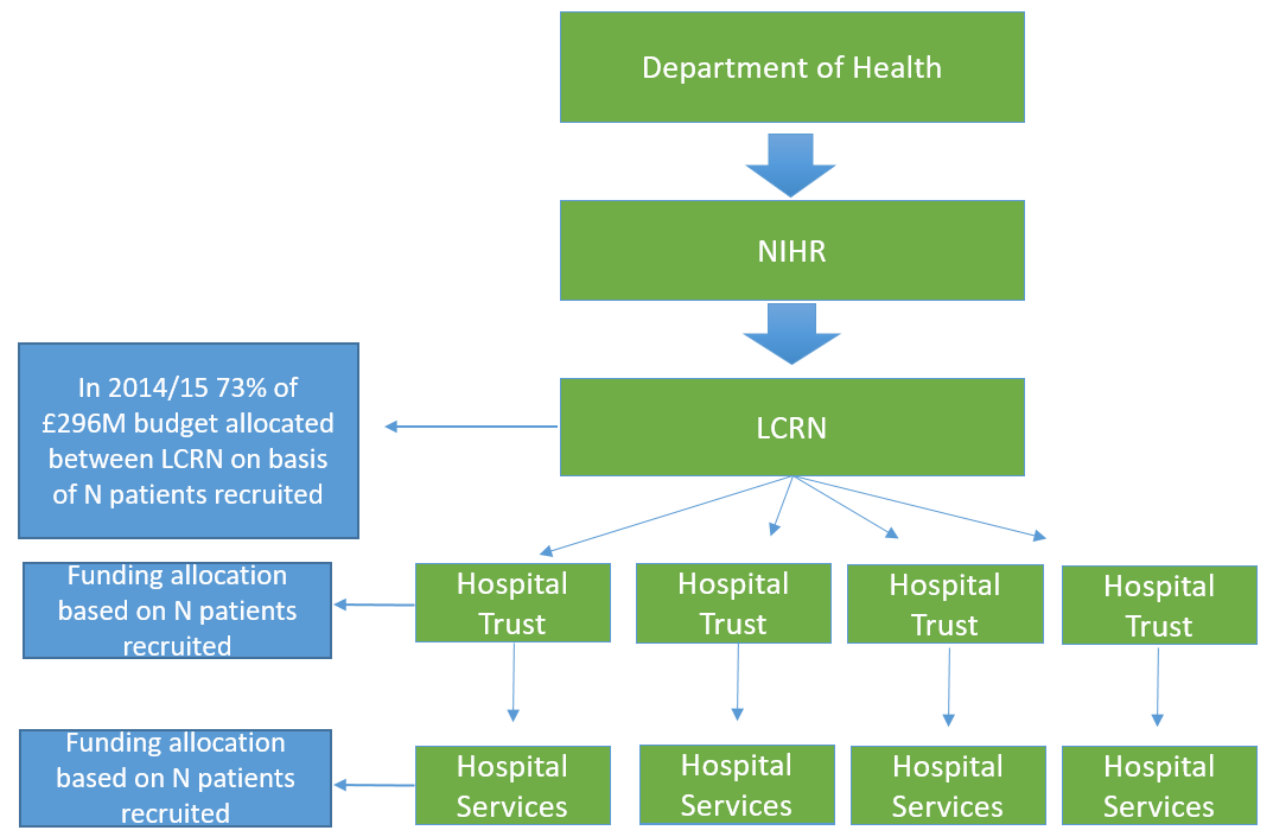

Participants reported that the primary focus on the number of patients recruited to studies was creating pressure to devalue factors not measured, and that this could pose an increased risk to patient experience and safety. This concern was explicitly raised by some research nurses:

I mean I think there's a real problem in [the recruitment indicator] - essentially that's one of the only metrics that's recognised by NIHR. So there's no measure of quality, there's no measure of safety in any of these processes. And so I think, you know, if you were actually looking at patient-reported experience during a study, I mean I think that would be a really interesting thing to look at, because I think in some studies you may have absolutely fantastic recruitment rates, but those patients may have actually had a very poor experience of taking part in research. And they may never want to take part in a research study again. They may tell their friends 
and family that they had a terrible experience. And so overall, I think, you have a negative outcome. But I think that that's a real shortfall in terms of NIHR.

\section{RN1, Service D}

Clinical nurses in this service also articulated concern about what they perceived as inappropriate levels of pressure on patients to take part in research and the potential for practice to veer towards the edge of safety where clinical issues that emerged during research visits were not dealt with. While this also highlights issues of communication between clinical and research staff, the clinical nurses explicitly suggested that this behaviour could, at least in part, be explained by the pressure on their research colleagues to recruit:

I get the impression that they're under a lot of pressure to recruit patients to the studies. And therefore they're being driven from behind, by the doctors who are doing research, that they feel a pressure to get the patients into the studies. And if the patients aren't recruited, the doctors want to know why, because they are looking for certain numbers. So I do realise it's not easy for them either.

\section{CN1, Service D}

Research nurses in Service C also reported that they experienced pressure to recruit patients to research and felt that appropriate recruitment was being devalued by the Trust owing to the financial incentives attached to patient recruitment nationally:

The pressure is still there to recruit quickly and not necessarily in the appropriate manner [...]. For [the Trust] it's still very much, it's numbers, it's not a patient, it's a number, it's money that they're going to get.

RN3, Service C 
These accounts suggest that the local management culture was, in keeping with NPM doctrine, performance-driven and target-led. In all services, there was frustration that, as staff perceived it, the focus was increasingly on performance managing research staff rather than on identifying and addressing barriers to undertaking research. For example:

RD3: There's enough pressure to get patients to studies, to deliver the scientific target objective, without also sort of people in clinic then worrying about the fact that they haven't recruited a patient that day, they've only got fifteen days left to recruit. I don't think it's totally helpful.

RD1: If [target] helps to speed up the $R \& D$ process, which is very protracted and, you know. I mean all the paperwork that we are overburdened with as part of research is a major obstacle. And puts probably ninety-five percent of people off from doing research in the first place. So if the targets help to speed the paperwork process up and makes people think in $R \& D$ how to facilitate the process better, then that's great. But if it has a detrimental effect on people who are actually doing the research at the coalface, then obviously that's not good.

\section{Service B}

As alluded to in the first quote above, the national NIHR system does not routinely measure research participant safety or experience. Patient experience is measured in clinical services but the NHS's 'Friends and Family Test' (FFT), which seeks patient feedback, does not include patients' experiences of research. Neither is it possible in this survey to identify which patients are taking part in research. The NHS requires staff to report 'Adverse Events' and breaches of Good Clinical Practice (GCP) (including through mandatory externally 
chaired monitoring committees for interventional studies) but none of the concerns or incidents reported in this study reached this threshold. Therefore, the system has limited capacity to learn (Senge et al., 1994) through the activities performance managed. As discussed above, NPM-style systems have been criticised for the barriers they present to learning (Van Dooren et al., 2015). A key public inquiry in England into sub-standard hospital care was critical of over-reliance on quantitative indicators and recommended that to prevent future similar tragedies hospital needed to take greater heed of the insights of staff, patients and carers by paying greater attention to narratives (Francis, 2013). Further, research with senior healthcare leaders in the NHS has found widespread agreement concerning the limitations of formal metrics for monitoring quality and safety and the importance of incorporating 'soft intelligence' (Martin et al., 2015). Yet the focus here, in the context of health research, formally at least, remains on simple quantitative indicators.

There was also widespread frustration amongst participants that the simple performance indicator did not reflect the variety of study types. They reported that the NIHR's 'complexity weighting' (which gives more weight to interventional compared to observational studies) was insufficient to account for the duration of follow up in studies, the level of intervention (for example, taking a routine blood sample compared to inserting a medical device) nor the number of eligible patients. Participants reported that high or low levels of recruitment in one year, owing to the type of study, rather than staff efforts at recruitment, could lead to an upward or downward spiral of resources. For example:

RD1: I think it's ridiculous, you know, just because we haven't recruited in one year, for the next year you're going to lose research staff so of course next year you're going to have less recruitment. 
$[\ldots]$

RN1: Two years ago we had an incredibly quick recruiting one that basically it didn't need much criteria, you could go to clinic and you could recruit and we recruited hundreds. We haven't got that study any more, it stopped, it went into follow-up. CRN think that therefore we're not doing anything because we're not recruiting. Obviously those hundred patients are still in follow-up, we're still managing those patients. Research doesn't stop when you stop recruiting. And, for me, that's, they don't understand that at all. And if they do understand it, they don't care-it's all about recruitment and not about the whole thing.

\section{Service A}

This issue is echoed in a recent Cancer Research UK study (Brown et al, 2015), which argued that the system is favouring specialisms that are naturally better placed to recruit high numbers of patients due to high numbers of studies with large eligible populations and short follow-up times with patients. Further research is required to investigate this claim but our study adds weight to CRUK's concerns. Certainly, this approach is in keeping with the competition components of NPM, which include 'reward and sanctions' in the form of published performance (reputational effects) and the award of bonuses dependent on performance (Bevan \& Hood, 2006). It further ascribes to the NPM 'best to best' budgetary allocation principle for measured performance (Bevan \& Hood, 2006, p. 519). Such principles are not without controversy. For example, the 'best to best' principle can be challenged by the rival principles of 'equal shares' or 'best to worst' (giving the most to the weakest or most disadvantaged units) (Bevan \& Hood, 2006). 


\section{Flexibilization of research nurse workforce}

NPM is characterised by greater flexibility in hiring staff (Hood, 1991). The findings suggest flexibilization of the research nurse workforce, in keeping with NPM doctrine (Hood, 1991). Participants reported that research nurse posts funded by LCRN were short-term contracts in which nurses could be redeployed between services and hospitals in the Trust based on the recruitment success of services in the previous year. Participants in all services reported problems recruiting research nurses, particularly those with clinical experience relevant to the specialism. Service B for example, was, at the time of this study, on the fourth round of advertising a research nurse position. Participants suggested that research nurse posts were less attractive to 'quality' candidates in part because research nurses were liable to be redeployed annually.

In addition, participants in service $\mathrm{D}$ reported that the narrowing of the role of research nurses due to the adoption of crude performance indicators was affecting the retention of research nurses. In this service, research nurses reported that morale and retention was down because they felt more like 'agents' than nurses as their role had become so focused on recruitment.

\section{Gaming}

Previous research has identified 'gaming', the deliberate manipulation of behaviour to secure strategic advantage (Smith, 1995), as an unwanted consequence of the performance measurement and management regime typical of NPM (Bevan \& Hood, 2006; Greener, 2005). It has been argued that performance management can distort the priorities and practices of those delivering services, paradoxically, producing worse outcomes for the intended beneficiaries (Lowe, 2013). Various gaming strategies have been identified in health care and other public services. One strategy involves 'output distortion' (Hood, 2006, p. 516), 
in which an organisation may experience 'measure fixation', pursing success as measured rather than as intended (Smith, 1995).

In our study, some staff explicitly reported that the system was encouraging gaming, including 'output distortion' (Hood, 2006) and 'measure fixation' (Van Dooren et al., 2015). It was asserted that the Trust was prioritizing studies that would accrue large numbers of patients, attracting high levels of funding, rather than prioritising on the basis of scientific output or patient benefit. Further it was reported that observational studies of little or no scientific benefit were being undertaken for the purpose of increasing patient recruitment, with no use made of the data:

The biggest problem with it is that, you know, if you're doing a revolutionary study that's kind of changed the world, you might only have ten patients in it. You know [a specialism specific study] the holy grail of [specialism], and I published in New England Journal of Medicine with ten patients in it, that would change the world of [specialism]. I'm nowhere near doing that by the way. And that study, you know, would have low priority at the moment because there would only be ten patients [...] So there's a lot of gaming that goes on. I mean doctors are very, very good at gaming. They work out, "Okay what do I need to do to score high?" And then they do it.

\section{RD4, Service D}

Below a research nurse and research doctors discuss their concerns in relation to the NIHR 70 day target to recruit the first patient, suggesting that in their experience this target is being gamed and potentially has a detrimental impact on research:

RN1 I think, having set up studies for the national studies, I felt we've seen that these $R \& D$ targets really stop - well, they don't always, you know, promote research. So one centre, we know, won't even fill out all the $R \& D$ [forms] and get signed up until they 
have a patient [...] Therefore they're not recruiting patients. And that's really, feels like something that $R \& D$ have put in place to promote research and actually it's just stopping it.

RD1: I agree. I think the [seventy day] target is actually a barrier to research.

RD2: Absolutely.

RD1: People want to do research, that's why they're taking on the study. But they don't need the added pressure of, "I need to recruit a patient or I'm going to be penalised." You know, if the patients aren't there, the patients aren't there. If you can't find the patient, why should you be penalised? You can't force patients and recruit inappropriate patients into studies because of the fear of not meeting a target.

Service A

Gaming of this kind, 'output distortion', has previously been reported in the NHS where, for example, treatments or training commenced but were not completed in situations in which the performance management indicator only measured commencement (Hood, 2006, p. 518). Its presence indicates, not only the persistence of NPM style management practices but the potential continuation of unwanted effects in a sector exemplifying the late-adoption of these management practices.

\section{Discussion \& Conclusion}

The question of NPM resilience or decline is important because NPM-style performance management has been shown to have a liability for unintended and dysfunctional effects. The 
UK health sector has long been seen as a high impact sector for NPM (Ferlie et al., 1996). Meanwhile, the R\&D domain of the NHS has been growing in importance for about twenty years (Feehally, 2002), a development reinforced by the establishment of the NIHR. Therefore our study investigates an important theoretical debate in an under-studied, relatively new empirical context. While we acknowledge that this is a small scale study, it is one of the few to investigate NIHR as an organisation and consider the managerial practices that populate this important new domain (see also Shaw \& Greenhalgh, 2008). Our findings begin to fill this gap in the literature.

Our analysis of NIHR structures and policy documents combined with the case study of a high-performing NHS Trust contributes to the theoretical NPM literature by suggesting that the case of medical research in England's NHS contradicts claims of the demise of NPM. On the contrary, it provides an example of the recent adoption of NPM as an important component of the managerial system in the large and important health research sector, since the establishment of the NIHR in 2006.

Our findings are in keeping with wider research evidencing the resilience of NPM (De Vries \& Nemec, 2013; Ferlie \& Ongaro, 2015; Lodge \& Gill, 2011; Trenholm \& Ferlie, 2013). In terms of NPM's competition components, the publication by NIHR of national league tables of patient recruitment by Trusts is in keeping with Dunleavy and colleagues' (2006) assertion that league tables are still spreading and is the main legacy of NPM. Both Dunleavy and colleagues (2006) and Osborne (2009) assert that there is evidence of improved performance measurement, including a move to service processes and outcomes from NPM's focus on service inputs and outputs (Osborne, 2009). However, the NIHR performance management system shows a clear national focus on the output of patient recruitment. Performance management remains in the traditional 'audit' style (Power, 1997), encapsulating a reductionist, quantitative approach. Despite the knowledge base, the national regime suffers 
the usual bias towards selecting measurable, available indicators resulting in concept reduction and the risk of reconfirming or reinforcing preconceived standpoints, rather than providing an account of performance (Van Dooren et al., 2015).

Both Osborne (2009) and Bryson (2014) claim there has been a change in the value base from the efficacy of competition and the market-place in NPM to neo-corporatism in New Public Governance (Osborne, 2009) and democratic theory in Public Value Governance (Bryson et al., 2014). Yet the NIHR system illustrates that management of medical research at the national level has retained a focus on competition in a market-style environment, with monetary value attached to patients recruited and competition amongst LCRN for finite funding. The prevailing view of rationality in the NIHR performance system is 'economic man', self-interested decision makers incentivised through pay-by-performance, rather than the belief in public spiritedness beyond narrow self-interest. Overall then, the case of medical research in the English NHS would seem to empirically contradict claims of the demise of NPM.

As discussed, the NIHR's intent is to contribute research that will benefit patients and society, leading to improved outcomes in terms of health and wealth. While NIHR is keen to find evidence of impact, it acknowledges the challenges of demonstrating impact in the complex environment of health research (NIHR, 2018). Our study does not seek to contribute to the question of the impact of NIHR LCRN funding in terms of health and wealth outcomes and we make no claims in this regard. However, our examination of the LCRN NIHR system in a high-performing NHS Trust suggests that, in keeping with the NPM literature (Bevan \& Hood, 2006; Hood \& Peters, 2004, p. 269; Mannion \& Braithwaite, 2012; Senge et al., 1994; Smith, 1995), this performance management system may produce unwanted and dysfunctional consequences. Research nurses and clinical nurses' perception that the system was encouraging, and indeed pressuring research staff, to narrowly focus on recruitment at 
the expense of broader organisational objectives, can be categorised as a concern that the system is encouraging 'measure fixation' (Smith, 1995). The assertion of some doctors that 'gaming' was taking place to increase the financial gains to the Trust from recruitment while contributing little to meaningful research outcomes is also in keeping with previous research on NPM (Hood, 2006). These staff concerns regarding the reduction of the rather intangible asset of medical knowledge creation into simple, recruitment-focused indicators, reflect the concern that NPM models may encourage organisations to "[hit] the target and miss the point" (Bevan \& Hood, 2006, p. 521). In this empirical context, managers may focus on the number of patients recruited and miss factors not counted, including patient retention in studies, patient experience and safety and staff morale and retention. These findings contribute to the literature evidencing unintended consequences of NPM performance management systems (Bevan \& Hood, 2006; Hood \& Peters, 2004, p. 269; Mannion \& Braithwaite, 2012; Senge et al., 1994; Smith, 1995) and highlight a need for further investigation in order to explore the potential disconnect between system information (what we believe we know) and practice (what is experienced).

The political realities of this entrenched NPM institutional landscape, demand public sector accountability, defined in terms of demonstrating one's performance (Lewis, 2016).

Specifically, the accountability regime of NPM logic mandates that the link between medical research inputs (public money) and outcomes (health and wealth) be demonstrated.

Performance data for the latter are difficult, if not impossible to reasonably demonstrate, and outputs (e.g. patient recruitment) therefore become a more realistic goal for performance measurement. Yet in this process of making accountability and measurement possible the very concept of interest is reduced and understanding of practice obscured. In this sense performance regimes in NPM may serve the purpose of making organisations accountable, but not necessarily for what matters. 
Proponents of NPM might argue that use of alternative output oriented measures (e.g. research publications rather than patient recruitment), could address the problems of measurement and management we have highlighted. Yet our study highlights that these would likely be insufficient to identify unintended and unanticipated consequences. The concerns raised by staff in this research study highlight the importance of 'soft intelligence' (Bevan \& Hood, 2006; Mannion \& Braithwaite, 2012) and the need to understand how the system is performing beyond pre-defined indicators.

A detailed discussion of potential alternatives to NPM management of health research is beyond the scope of this paper. However, some of the broader Network Governance (NG) ideas explored earlier provide a basis for further thought about what a non-NPM model of health research management might look like. These ideas would stress the need for active patient participation in the research process, including in the early stages of study design and within the spirit of co-production. There would likely be active and regular consultation with patient orientated third sector organizations at study and also at a wider research policy level. The views and experiences of more junior staff (e.g. research nurses) would also be seen as important to capture through such techniques as focus groups and quality circles. It is worth noting that, given that clinically-focused doctors and nurses (as well as research-focused staff themselves) had concerns about research practice, our study suggests the need to seek data about the research process, not just from research-focused staff, but also from clinicallyfocused staff who work alongside researchers. In an alternative model to NPM the quality of the experience of the research process by patients and staff would be seen as important as well as hitting quantitative recruitment targets. There would also likely be an active process of organizational learning, with debriefs at the end of research cycles to derive ideas for continuous improvement in future research management. 
A further intriguing question is 'why?' this NPM embeddedness was found in the NIHR which is a relatively recently created agency. Future work should look further at its governance, strategy, operations and culture. It is an agency under the clear direction (indeed integrated within) of the DoH and with clear targets to meet. DoH has previously been seen as a pro NPM outlier within Whitehall (Greer \& Jarman, 2007).

Overall, this article raises concerns regarding the management of medical research in the English health research system. It contributes to the body of research suggesting that NPM is far from dead but rather resilient (De Vries \& Nemec, 2013; Ferlie \& Ongaro, 2015; Lodge \& Gill, 2011) and continues to be adopted in a key UK public service. Our research also contributes to the large body of evidence raising concerns about the potential for unintended and dysfunctional consequences. Given the resilience of NPM in the face of the large body of critical literature, we might question the extent to which academic debate and evidence is having an impact on public managers and policy makers and alternative models are perceived as viable alternatives.

This research has some limitations that should be noted. Our study is of the national NIHR system for performance managing research and our findings demonstrate that this system conforms to key tenets of NPM, evidencing NPM resilience in a core service in the UK. We examined potential consequences of this system by focusing in-depth on one high performing NHS Hospital Trust. In terms of the unintended consequences highlighted by the Trust-level study, we make no claims regarding population-level generalisabilty. Rather our study highlights the potential for these unintended consequences to occur. Further research is required to establish prevalence of these consequences. Research is also required to understand from the perspective of policy makers and mangers why they continue to adopt NPM and how they understand and apply the evidence on it. Further, we did not empirically investigate the functioning of NIHR-LCRN in 2006 and so do not claim to provide an in- 
depth illustration of its functioning at this time point. Nonetheless, the foundational

documents we have cited in this paper suggest that many of the characteristics of NPM were

evident its institutional set up at this time and suggest consistency between 2006 and today.

\section{References}

Bevan, G., \& Hood, C. (2006). What's measured is what matters: targets and gaming in the English public health care system. Public administration, 84(3), 517-538.

Brown, H., Hewison, A., Gale, N., Snelling, I., \& Shneerson, C. (2015). Every Patient a Research Patient? Evaluating the current state of research in the NHS. Retrieved from https://www.cancerresearchuk.org/sites/default/files/cruk_every_patient_may2015_web.p df

Bryman, A. (2008). Social Research Methods. New York: Oxford University Press.

Bryson, J. M., Crosby, B. C., \& Bloomberg, L. (2014). Public Value Governance: Moving Beyond Traditional Public Administration and the New Public Management. Public Administration Review, 74(4), 445-456. doi:10.1111/puar.12238

Christensen, T., Lie, A., \& Lægreid, P. (2008). Beyond new public management: agencification and regulatory reform in Norway. Financial Accountability \& Management, 24(1), 15-30.

Commission for Health Improvement. (2003). What CHI has found in ambulance trusts. London: Stationery Office, 2003. . Retrieved from London:

www.healthcarecommission.org.uk/NationalFindings/NationalThemedReports/Ambulance/f s/en

Commission for Health Improvement. (2004). What CHI Has Found in: Acute Services. Retrieved from London: http://www.healthcarecommission.org.uk/NationalFindings/NationalThemedReports/

Cooksey, D. (2006). A review of UK health research funding. Retrieved from Norwich:

Croxson, B., Hanney, S., \& Buxton, M. (2001). Routine monitoring of performance: what makes health research and development different? Journal of Health Services Research \& Policy, 6(4), 226-232. doi:10.1258/1355819011927530

Dawson, S., \& Dargie, C. (1999). New public management: An assessment and evaluation with special reference to UK health. Public Management an International Journal of Research and Theory, 1(4), 459-481.

Day, P., \& Klein, R. (1990). Inspecting the Inspectorates. Retrieved from London:

De Vries. (2010). Is New Public Management Really Dead? OECD Journal on Budgeting, 1, 87-91

De Vries, M., \& Nemec, J. (2013). Public sector reform: an overview of recent literature and research on NPM and alternative paths. International Journal of Public Sector Management, 26(1), 416. doi:doi:10.1108/09513551311293408

Department of Business, I. a. S. (2011). Innovation and Skills Strategy for UK Life Sciences. Retrieved from London:

Department of Health. (2000). An organisation with a memory. Retrieved from London: https://www.aagbi.org/sites/default/files/An\%20organisation\%20with\%20a\%20memory.pdf

Department of Health. (2006). Best Research for Best Health: a new national health research strategy. Retrieved from London: 
https://www.gov.uk/government/uploads/system/uploads/attachment_data/file/136579/d h_4127153.pdf

Department of Health. (2008). High Quality Care for All. Retrieved from London:

Dunleavy, P., Margetts, H., Bastow, S., \& Tinkler, J. (2006). New Public Management Is Dead-Long Live Digital-Era Governance. Journal of Public Administration Research and Theory, 16(3), 467-494. doi:10.1093/jopart/mui057

Feehally, J. (2002). Culyer, research governance, and all that. Postgraduate Medical Journal, 78(926), 703-705.

Ferlie, E. (2013). Making Wicked Problems Governable?: The Case of Managed Networks in Health Care. Oxford: Oxford University Press.

Ferlie, E., Ashburner, L., Fitzgerald, L., \& Pettigrew, A. (1996). The New Public Management in Action. Oxford: Oxford university press.

Ferlie, E., \& Fitzgerald, L. (2002). The sustainability of the New Public Management in the UK. In K. McLaughlin, S. Osborne, \& E. Ferlie (Eds.), New Public Management : Current trends and future prospects. London: Routledge.

Ferlie, E., Fitzgerald, L., McGivern, G., Dopson, S. U. E., \& Bennett, C. (2011). Public Policy Networks and 'wicked problems': a nascent solution? . Public Administration, 89(2), 307-324. doi:10.1111/j.1467-9299.2010.01896.x

Ferlie, E., \& Ongaro, E. (2015). Strategic Management in Public Services Organizations: Concepts, Schools and Contemporary Issues. London: Routledge.

Francis, R. (2013). Report of the Mid Staffordshire NHS Foundation Trust Public Inquiry. Retrieved from

http://webarchive.nationalarchives.gov.uk/20150407084231/http://www.midstaffspublicin quiry.com/report

Greener, I. (2005). Health management as strategic behaviour: Managing medics and performance in the NHS. Public Management Review, 7(1), 95-110.

Greer, S. L., \& Jarman, H. (2007). The Department of Health and the civil service. London Nuffield Trust

Griffiths, R. (1983). NHS Management Enquiry'. Retrieved from London:

Hanney, S. R., \& González Block, M. A. (2006). Building health research systems to achieve better health. Health Res Policy Syst, 4(10), 6.

Henkel, M. (1991). The new 'evaluative state'. Public Administration, 69(Spring), 121-136.

Hood, C. (1991). A public management for all seasons. Public Administration, 69(1), 3-19.

Hood, C. (2006). Gaming in targetworld: the targets approach to managing British public services. Public Administration Review, 66(4), 515-521.

Hood, C., \& Peters, G. (2004). The Middle Aging of New Public Management: Into the Age of Paradox? Journal of Public Administration Research and Theory, 14(3), 267-282. doi:10.1093/jopart/muh019

Kelman, S., \& Friedman, J. N. (2009). Performance Improvement and Performance Dysfunction: An Empirical Examination of Distortionary Impacts of the Emergency Room Wait-Time Target in the English National Health Service. Journal of Public Administration Research and Theory, 19(4), 917-946. doi:10.1093/jopart/mun028

Lester, H. E., Hannon, K. L., \& Campbell, S. M. (2011). Identifying unintended consequences of quality indicators: a qualitative study. BMJ Quality \& Safety, 20(12), 1057-1061. doi:10.1136/bmjqs.2010.048371

Lewis, J. M. (2016). The Paradox of Health Care Performance Measurement and Management. In E. Ferlie, K. Montgomery, \& A. Reff Pedersen (Eds.), The Oxford Handbook of Health Care Management (pp. 375). Oxford.

Lodge, M., \& Gill, D. (2011). Toward a New Era of Administrative Reform? The Myth of Post-NPM in New Zealand. Governance, 24(1), 141-166. doi:10.1111/j.1468-0491.2010.01508.x 
Loveday, B. (2008). Performance management and the decline of leadership within public services in the United Kingdom. Policing, 2(1), 120-130.

Lowe, T. (2013). New development: The paradox of outcomes -the more we measure, the less we understand. Public Money \& Management, 33(3), 213-216.

Mannion, R., \& Braithwaite, J. (2012). Unintended consequences of performance measurement in healthcare: 20 salutary lessons from the English National Health Service. Internal Medicine Journal, 42(5), 569-574. doi:10.1111/j.1445-5994.2012.02766.x

Martin, G., Currie, G., Weaver, S., Finn, R., \& McDonald, R. (2017). Institutional complexity and individual responses: delineating the boundaries of partial autonomy. Organization Studies, 38(1), 103-127.

Martin, G., McKee, L., \& Dixon-Woods, M. (2015). Beyond metrics? Utilizing 'soft intelligence' for healthcare quality and safety. Social Science \& Medicine, 142, 19-26. doi:http://dx.doi.org/10.1016/j.socscimed.2015.07.027

Mays, N., \& Pope, C. (2000). Assessing quality in qualitative research. BMJ, 320(7226), 50-52. doi:10.1136/bmj.320.7226.50

McCann, L., Granter, E., Hassard, J., \& Hyde, P. (2015). "You Can't Do Both-Something Will Give": Limitations of the Targets Culture in Managing UK Health Care Workforces. Human Resource Management, 54(5), 773-791. doi:10.1002/hrm.21701

Moynihan, D. P., \& Pandey, S. K. (2005). Testing How Management Matters in an Era of Government by Performance Management. Journal of Public Administration Research and Theory, 15(3), 421-439. doi:10.1093/jopart/mui016

National Advisory Group on the Safety of Patients in England. (2013). A Promise to Learn: A Commitment to Act'. Retrieved from London:

Newman, J. (2001). Modernizing governance: New Labour, policy and society. London Sage.

NIHR. (2014a). History of the NIHR. Retrieved from http://www.nihr.ac.uk/about/history-of-thenihr.htm

NIHR. (2014b). NHS trust research activity league table 2013/14. Retrieved from http://www.theguardian.com/healthcare-network-nihr-clinical-research-zone/table/nhstrust-research-activity-league-table-2013-14

NIHR. (2014c). NIHR Local Clinical Research Network Funding Allocations 2014/15. Retrieved from https://www.crn.nihr.ac.uk/wp-

content/uploads/About\%20the\%20CRN/NIHR\%20CRN\%20Funding\%20Allocations\%20201415_Public\%202014-04-07\%20FINAL\%20(V2.0).pdf

NIHR. (2017a). How we are managed. Retrieved from https://www.nihr.ac.uk/about-us/how-weare-managed/

NIHR. (2017b). NIHR Local Clinical Research Network Funding Allocations 2017/18 Retrieved from London: https://www.nihr.ac.uk/about-us/how-we-are-managed/managingcentres/crn/NIHR\%20CRN\%20Funding\%20Allocations\%20201718\%20PUBLIC\%20VERSION\%20v3.0\%20FINAL.pdf

NIHR. (2017c). NIHR Research Activity League Table 2015-2016. Retrieved from https://www.nihr.ac.uk/research-and-impact/nhs-research-performance/leaguetables/league-table-data.htm

NIHR. (2017d). Our purpose. Retrieved from https://www.nihr.ac.uk/about-us/our-purpose/ NIHR. (2017e). Performance in Initiating and Delivering Clinical Research Retrieved from London: https://www.nihr.ac.uk/research-and-

impact/documents/PID\%20Documents/Guidance\%20Documents/Performance\%20in\%20Init iating\%20and\%20Delivering\%20Guidelines\%20Published.pdf

NIHR. (2018). Impact. Retrieved from https://www.nihr.ac.uk/research-and-impact/impact/

Osborne, S. P. (2006). The New Public Governance? . Public Management Review, 8(3), 377-387.

Osborne, S. P. (2009). The new public governance? emerging perspectives on the theory and practice of public governance. London: Routledge. 
Ouchi, W. G. (1977). The relationship between organizational structure and organizational control. Administrative science quarterly, 22(1), 95-113.

Pollitt, C., \& Dan, S. (2011). The impacts of the New Public Management in Europe: a meta-analysis. Brussels: Coordinating for Cohesion in the Public Sector of the Future.

Power, M. (1997). The Audit Society: Rituals of Verification. Oxford: Oxford University Press.

Rhodes, R. A. (1997). Understanding governance: Policy networks, governance, reflexivity and accountability. Buckingham: Open University Press.

Rhodes, R. A. (2007). Understanding governance: Ten years on. Organization Studies, 28(8), 12431264.

Senge, P., Roberts, R., Ross, R., Smith, B., \& Kleiner, A. (1994). The Fifth Discipline Fieldbook: Strategies and Tools for Building a Learning Organization. New York: Doubleday.

Shaw, S. E., \& Greenhalgh, T. (2008). Best research - For what? Best health - For whom? A critical exploration of primary care research using discourse analysis. Social Science \& Medicine, 66(12), 2506-2519. doi:http://dx.doi.org/10.1016/j.socscimed.2008.02.014

Shore, C. (2008). Audit culture and Illiberal governance: Universities and the politics of accountability. Anthropological Theory, 8(3), 278-298. doi:10.1177/1463499608093815

Simonet, D. (2014). Assessment of new public management in health care: the French case. Health Research Policy and Systems, 12, 57. doi:10.1186/1478-4505-12-57

Smith, P. (1993). Outcome-related Performance Indicators and Organizational Control in the Public Sector1. British Journal of Management, 4(3), 135-151. doi:10.1111/j.14678551.1993.tb00054.x

Smith, P. (1995). On the unintended consequences of publishing performance data in the public sector. International Journal of Public Administration, 18(2-3), 277-310. doi:10.1080/01900699508525011

Spencer, L., Ritchie, J., \& O'Connor, W. (2003). Analysis: Practices, Principles and Processes. In J. Ritchie \& J. Lewis (Eds.), Qualitative Research Practice. London: SAGE.

Stoneman, P. (1999). Government spending on research and development in the UK. Fiscal Studies, 20(3), 223-259.

Tan, H. T. R., \& Harvey, G. (2016). Unpacking the Black Box: A realist evaluation of performance management for social services. Public Management Review, 18(10), 1456-1478.

Trenholm, S., \& Ferlie, E. (2013). Using complexity theory to analyse the organisational response to resurgent tuberculosis across London. Social Science \& Medicine, 93, 229-237. doi:http://dx.doi.org/10.1016/j.socscimed.2012.08.001

Van Dooren, W., Bouckaert, G., \& Halligan, J. (2015). Performance management in the public sector: Routledge.

Verbeeten, F. H. M., \& Speklé, R. F. (2015). Management Control, Results-Oriented Culture and Public Sector Performance: Empirical Evidence on New Public Management. Organization Studies. doi:10.1177/0170840615580014

Wankhade, P. (2011). Performance measurement and the UK emergency ambulance service: Unintended consequences of the ambulance response time targets. International Journal of Public Sector Management, 24(5), 384-402.

World Health Organization. (2004). World report on knowledge for better health: strengthening health systems. Retrieved from Geneva: 


\section{Disclosure statement}

The authors have no financial interest or benefit arising from the application of this research to declare.

\section{Acknowledgements}

The authors are grateful to the staff of the anonymous NHS Trust who generously gave of their time to share their experiences and perceptions. The authors further wish to thank the anonymous reviewers for their comments on earlier drafts of this paper.

The research was supported by the National Institute for Health Research (NIHR) Biomedical Research Centre at Guy's and St Thomas' NHS Foundation Trust and King's College London. The views expressed are those of the author(s) and not necessarily those of the NHS, the NIHR or the Department of Health 